\title{
EDITORIAL
}

\section{Covid-19: Navigating Scientific Uncertainty}

Syed Muhammad Imran Majeed, Rehma Ahsan Gilani

Alvin Toffler once wrote: "The illiterate of the $21^{\text {st }}$ century will not be those who cannot read and write, but those who cannot learn, unlearn, and relearn." This pandemic has proven his statement correct. The global academic community has learned a completely new culture of research, with torrents of data being released daily on preprint servers ${ }^{1,2}$ and dissected on platforms such as Slack and Twitter before formally peer reviewed. Fifty-five thousand viral genomes sequences of hCoV-19 shared on GISAID platforms to date ${ }^{3}$ that have been analyzed instantaneously, by a phalanx of evolutionary biologists who share their phylogenetic trees in preprints. Such advances have allowed scientists to trace and monitor the COVID-19 pandemic faster than any previous outbreak.

There is still more to learn. The scientist from the fields of epidemiology, virology and biomedical science are struggling to keep this outbreak under control. Estimation of R0, which have been an important part of characterizing pandemics, including the 2003 SARS pandemic, the $2009 \mathrm{H} 1 \mathrm{~N} 1$ influenza pandemic and the 2014 Ebola epidemic in West Africa, is something epidemiologists raced to nail down about SARS-CoV-2. There's uncertainty, for a number of reasons, about many of the factors that go into estimating R0. First, the incubation period of this viral pathogen is uncertain with an average 5-6 days and can be up to 14 days. ${ }^{4}$ Researchers cannot predict, without sentinel surveillance, the number of mild or asymptomatic cases that have been missed but nevertheless are spreading the disease. ${ }^{5}$ Secondly, majority of people who get infected, do recover and are likely to be immune. This alters population susceptibility and affects future trajectory of infection spread. Finally, susceptibility to disease in different communities varies based on their demographics, health conditions and different social structures. And hence, mathematical model accuracy, be it Institute for Health Metrics and Evaluation (IHME) $)^{6}$, Ferguson et.al ${ }^{7}$, Aleta et.al ${ }^{8}$, Hellewell et.al ${ }^{9}$ and Kessler et al models ${ }^{10}$, is constrained by our knowledge of the virus dynamics since many biologic features of transmission are hard to measure and remain unknown.

Another aspect of the Covid-19, which is reshaping the world of bioscience publishing, is the tension between rapid speed of research publication verses scientific rigor. This has raised serious issues regarding data integrity. The Lancet and NEMJ had had to retract some publication on this account for example, Hydroxychloroquine or chloroquine with or without a macrolide for treatment of COVID-19: a multinational registry analysis ${ }^{11}$ and Cardiovascular Disease, Drug Therapy, and Mortality in Covid $-19^{12}$, because independent auditors were unable to validate the primary data sources. This is of concern in the middle of a global health emergency. ${ }^{13}$

Finally, this crisis has also altered our perspective. An important feature of our ongoing experience is what anthropologist Jane Guyer termed "enforced presentism", a feeling of being stuck in the present, combined with an inability to plan ahead. ${ }^{14}$ The question is how do we reclaim our future? The past has provided us a prologue for discussion, whether it is the biological origins of a potential pandemic or its social repercussions, it is up to us to reorder the society in dramatic ways, for better or worse.

\section{Editor-in-Chief}

doi: http://doi.org/10.37185/LnS.1.1.127

\section{REFERENCE}

1. biorxiv.org[Internet]. UK: COVID-19 SARS-CoV-2 preprints from bioRxiv. [updated 2020 July 12]. Available from: https://www.biorxiv.org/.

2. natureindex.com[Internet]. China: COVID-19 research update: How peer review changed the conclusions of a coronavirus preprint. 
[updated 2020 July 16]. Available from: https://www.natureindex.com/.

3. gisaid.org[Internet]. USA: hCoV-19 genomic sequences: Available from: https://www.gisaid.org/.

4. who.int[Internet]. USA: Coronavirus disease 2019 (COVID-19) Situation Report-73. [updated 2020 April 2]. Available from: https://www.who.int/.

5. Mahtani KR, Heneghan C, Aronson JK. What is the evidence for social distancing during global pandemics? A rapid summary of current knowledge. 2020.

6. covid19.healthdata.org[Internet]. USA: COVID-19 Projections. [updated 2020 July 7]. Available from: https://covid19.healthdata.org/.

7. Ferguson NM, Laydon D, Nedjati-Gilani G, Imai N, Ainslie K, Baguelin M, et al. Impact of non-pharmaceutical interventions (NPIs) to reduce COVID-19 mortality and healthcare demand. 2020.

8. Aleta A, Martin-Corral D, y Piontti AP, Ajelli M, Litvinova M, Chinazzi M, et al. Modeling the impact of social distancing, testing, contact tracing and household quarantine on second-wave scenarios of the COVID-19 epidemic. medRxiv. 2020.

9. Hellewell J, Abbott S, Gimma A, Bosse NI, Jarvis Cl, Russell TW, et al. Feasibility of controlling COVID-19 outbreaks by isolation of cases and contacts. The Lancet Global Health. 2020; 8: e488-96.

10. Kissler SM, Tedijanto C, Goldstein E, Grad YH, Lipsitch M. Projecting the transmission dynamics of SARS-CoV-2 through the postpandemic period. Science. 2020;368: 860-8.

11. Mehra MR, Desai SS, Ruschitzka F, Patel AN. Hydroxychloroquine or chloroquine with or without a macrolide for treatment of COVID-19: a multinational registry analysis. The Lancet. 2020.

12. Mehra MR, Desai SS, Kuy S, Henry TD, Patel AN. Retraction: Cardiovascular Disease, Drug Therapy, and Mortality in Covid-19. N EngI J Med. 2020; 382: 2582.

13. theguardian.com[Internet]. USA: Covid-19: Lancet retracts paper that halted hydroxychloroquine trials. [updated 2020 June 13]. Available from: https://www.theguardian.com/.

14. theconversation.com[Internet]. Australia: Coronavirus: how the pandemic has changed our perception of time. [updated 2020 May 28]. Available from: https://theconversation.com/. 